\title{
Correction to: Combining health insurance funds in a fragmented context: what kind of challenges should be considered?
}

\author{
Mohammad Bazyar ${ }^{1 *}$, Arash Rashidian²,3, Minoo Alipouri Sakha², Mohammad Reza Vaez Mahdavi ${ }^{4}$ and \\ Leila Doshmangir ${ }^{5,6}$
}

\section{Correction to: BMC Health Serv Res https://doi.org/10.1186/s12913-019-4858-7}

In the original publication of this article [1], there are two corrections:

1. The Fig. 1 is mistakenly replaced by Fig. 2 in the pdf version, so that the Fig. 1 and Fig. 2 are the same. This error is caused by a typesetting mistake. The corrected Fig. 1 is shown below:

2. Arash Rashidian has another affiliation, which was missing in the original article. The author details are revised as below:

Mohammad Bazyar ${ }^{1 *}$, Arash Rashidian ${ }^{2,3}$, Minoo Alipouri Sakha ${ }^{2}$, Mohammad Reza Vaez Mahdavi ${ }^{4}$ and Leila Doshmangir ${ }^{5,6}$

${ }^{1}$ Department of Health Promotion, Faculty of Health, Ilam University of Medical Sciences, Ilam, Iran.

${ }^{2}$ Department of Health Management and Economics, School of Public Health, Tehran University of Medical Sciences, Tehran, Iran.

3 Director of Information, Evidence and Research Department, World Health Organization Regional Office for the Eastern Mediterranean, Cairo, Egypt.

4 Department of Physiology, School of Medicine, Shahed University, Tehran, Iran.

5 Department of Health Policy and Management, Tabriz Health Services Management Research Center,
Iranian Center of Excellence in Health Management, School of Management and Medical Informatics, Tabriz University of Medical Sciences, Tabriz, Iran.

6 Social Determinants of Health Research Center, Health Management and Safety Promotion Research Institute, Tabriz University of Medical Sciences, Tabriz Iran.

The original article has been updated.

The original article can be found online at https://doi.org/10.1186/s12913019-4858-7

* Correspondence: bazyar.mohamad@gmail.com

${ }^{1}$ Department of Health Promotion, Faculty of Health, Ilam University of Medical Sciences, llam, Iran

Full list of author information is available at the end of the article

C C The Author(s). 2020 Open Access This article is licensed under a Creative Commons Attribution 4.0 International License, which permits use, sharing, adaptation, distribution and reproduction in any medium or format, as long as you give appropriate credit to the original author(s) and the source, provide a link to the Creative Commons licence, and indicate if changes were made. The images or other third party material in this article are included in the article's Creative Commons licence, unless indicated otherwise in a credit line to the material. If material is not included in the article's Creative Commons licence and your intended use is not permitted by statutory regulation or exceeds the permitted use, you will need to obtain permission directly from the copyright holder. To view a copy of this licence, visit http://creativecommons.org/licenses/by/4.0/ The Creative Commons Public Domain Dedication waiver (http://creativecommons.org/publicdomain/zero/1.0/) applies to the data made available in this article, unless otherwise stated in a credit line to the data. 


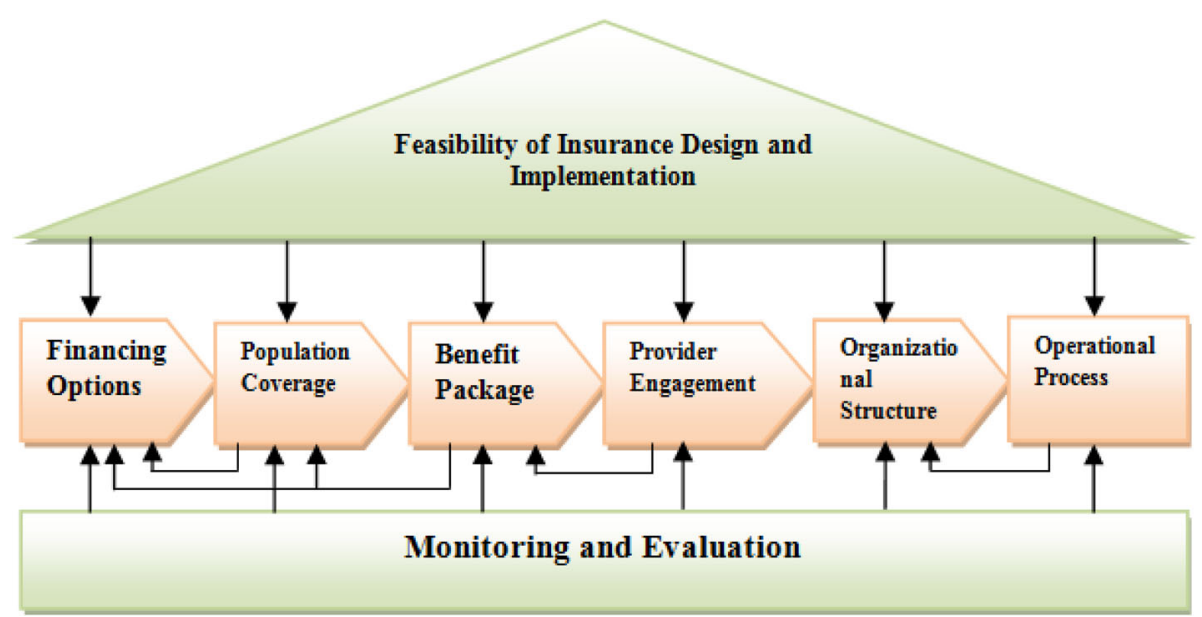

Fig. 1 Design Elements for a Health Insurance Scheme

\section{Author details}

'Department of Health Promotion, Faculty of Health, llam University of Medical Sciences, Ilam, Iran. ${ }^{2}$ Department of Health Management and Economics, School of Public Health, Tehran University of Medical Sciences, Tehran, Iran. ${ }^{3}$ Director of Information, Evidence and Research Department, World Health Organization Regional Office for the Eastern Mediterranean, Cairo, Egypt. ${ }^{4}$ Department of Physiology, School of Medicine, Shahed University, Tehran, Iran. ${ }^{5}$ Department of Health Policy and

Management,Tabriz Health Services Management Research Center, Iranian Center of Excellence in Health Management, School of Management and Medical Informatics, Tabriz University of Medical Sciences, Tabriz, Iran. ${ }^{6}$ Social Determinants of Health Research Center, Health Management and Safety Promotion Research Institute, Tabriz University of Medical Sciences, Tabriz, Iran.

Published online: 19 March 2020

\section{Reference}

1. Bazyar et al. BMC Health Services Research. 2020;20:26. 